\title{
Avaliação da aprendizagem: um olhar à luz das políticas neoliberais implementadas pela Base Nacional Comum Curricular
}

\author{
Learning assessment: a look in the light of neoliberal policies implemented by the Common \\ National Curriculum Base \\ Evaluación del aprendizaje: una mirada a la luz de las políticas neoliberales implementadas por \\ Base Curricular Nacional Común
}

Recebido: 28/08/2021 | Revisado: 04/09/2021 | Aceito: 15/09/2021 | Publicado: 16/09/2021

\author{
Rita Lee Lopes Vieira de Jesus \\ ORCID: https://orcid.org/0000-0003-2346-1750 \\ Universidade do Estado da Bahia, Brasil \\ E-mail: ritalee18@hotmail.com \\ Terezinha Camargo Magalhães \\ ORCID: https://orcid.org/0000-0002-6369-309X \\ Universidade do Estado da Bahia, Brasil \\ E-mail: tecamargo10@gmail.com
}

\begin{abstract}
Resumo
O presente artigo teve como objetivo refletir sobre a proposta da avaliação da aprendizagem a partir das políticas neoliberais implementadas pela Base Nacional Comum Curricular (BNCC). A metodologia desenvolveu-se através de uma pesquisa de campo de caráter qualitativo, tendo, como universo, três instituições de ensino da rede pública municipal de uma cidade baiana. Os recursos para coleta das informações foram análise documental e entrevista semiestruturada realizadas com três coordenadoras pedagógicas. O escrutínio das informações deu-se pela análise de conteúdo, agrupadas em duas categorias finais. Os resultados assinalam que a avaliação da aprendizagem na seara da BNCC aponta duas direções: enquanto referência ao gerencialismo e controle e como recurso pedagógico formativo. As participantes da pesquisa percebem a prática avaliativa como ferramenta fundamental ao acompanhamento da vida escolar do aluno, mas não mostraram segurança ao tratar desta na perspectiva da Base.
\end{abstract}

Palavras-chave: Avaliação da aprendizagem; Base Nacional Comum Curricular; Políticas neoliberais.

\begin{abstract}
This article aims to reflect on the proposal for evaluating learning from neoliberal policies implemented by the Common National Curriculum Base (BNCC). The methodology was developed through a qualitative field research, having as universe, three educational institutions of the municipal public network of a city in Bahia. The resources for collecting the information were document analysis and semi-structured interviews carried out with three pedagogical coordinators. The scrutiny of information took place through content analysis, grouped into two final categories. The results indicate that the assessment of learning in the BNCC field points to two directions: as a reference to managerialism and control and as a training pedagogical resource. The research participants perceive the evaluative practice as a fundamental tool for monitoring the student's school life, but they did not show security when dealing with this from the perspective of the Base.
\end{abstract}

Keywords: Learning assessment; Common National Curriculum Base; Neoliberal policies.

\section{Resumen}

Este artículo tiene como objetivo reflexionar sobre la propuesta de evaluación de aprendizajes de las políticas neoliberales implementadas por la Base Curricular Nacional Común (BNCC). La metodología se desarrolló a través de una investigación de campo cualitativa, teniendo como universo tres instituciones educativas de la red pública municipal de una ciudad de Bahía. Los recursos para la recolección de la información fueron el análisis de documentos y entrevistas semiestructuradas realizadas con tres coordinadores pedagógicos. El escrutinio de la información se realizó mediante análisis de contenido, agrupados en dos categorías finales. Los resultados indican que la evaluación de aprendizajes en el campo BNCC apunta en dos direcciones: como referencia al gerencialismo y control y como recurso pedagógico de formación. Los participantes de la investigación perciben la práctica evaluativa como una herramienta fundamental para el seguimiento de la vida escolar del estudiante, pero no mostraron seguridad al abordarla desde la perspectiva de la Base.

Palabras clave: Evaluación del aprendizaje; Base de Currículo Nacional Común; Políticas neoliberales. 


\section{Introdução}

Nos dias atuais, uma das principais pautas no cenário de educação brasileira tem sido o debate a respeito da Base Nacional Comum Curricular, a BNCC (2017), mobilizando muitos agentes constituintes da escola pública e privada. A Base carrega o intuito de definir as competências e os direitos de aprendizagem a serem desenvolvidos pelos estudantes, tendo em vista cada uma das fases da educação básica. O seu cumprimento exige uma série de mudanças nas práticas que formam o processo de ensino e aprendizagem, isto é, o que ensinar, como ensinar e de que modo avaliar.

Nesse contexto, "as aprendizagens essenciais definidas na BNCC devem concorrer para assegurar aos estudantes o desenvolvimento de dez competências gerais, que consubstanciam, no âmbito pedagógico, os direitos de aprendizagem e desenvolvimento" (BNCC, 2017, p. 10). Percebemos, com isso, que essas competências perpassam todo o processo educativo, desde a escolha dos conteúdos à forma como estes serão avaliados por variados instrumentos.

Discutir sobre a BNCC é, antes e acima de tudo, compreender os fundamentos epistemológicos, filosóficos, pedagógicos e históricos que a desenham como uma política de centralização do currículo. No entanto, essa parte do estudo compreende um desvelar de especificidades da história em âmbito mundial e nacional que, porsua vez, apresenta um cenário educacional demarcado por confrontos e relações de poder.

Os princípios e as diretrizes difundidas pelas agências internacionais, a Organização das Nações Unidas para a Educação, a Ciência e a Cultura (UNESCO), o Fundo das Nações Unidas para a Infância (UNICEF), o Programa das Nações Unidas para o Desenvolvimento (PNUD), o Banco Mundial e o Banco Interamericano de Desenvolvimento, foram fundamentais à consagração da Conferência de Educação para Todos no ano de 1990, ocorrida na Tailândia. Através dela, percebemos algumas preocupações com esse campo quando surgiram a Declaração Mundial de Educação para Todos e o Plano de Ação para a Satisfação das Necessidades Básicas de Aprendizagem. Esses documentos assinalam, pois, os compromissos e as responsabilidades assumidas pelo Estado e pela Sociedade Civil.

Retomando alguns fatos históricos e políticos, neste sentido, devemos citar o Movimento Global de Reforma da Educação, quando, em termos, deu força à eficiência dos sistemas de ensino a partirde um conjunto de projetos. Com essa reforma, observamos que uma das propostas das instituições globais, como o Banco Mundial, refere-se a um cenário educacional que garanta a estabilidade econômica dos países em desenvolvimento, dando ênfase às questões sociais. Esse fator, então, mostra o interesse em romper ou, pelo menos, amenizar a desigualdade tão vista, assim "a educação é tratada pelo Banco como medida compensatória para proteger os pobres e aliviar as possíveis tensões no setor social" (Fonseca, 1998, p. 95).

Neste sentido, Hypolito afirma com mais detalhes sobre a organização de reformas dos sistemas educacionais, quando enfatiza sobre a influência e articulação do Movimento Global de Reforma da Educação (GERM), que, desde 2001: "Está articulado em torno de três princípios da política educacional: padrões, prestação de contas e descentralização. [...] Em termos de padronização, basicamente está prescrito um currículo nacional que estabeleça padrões de qualidade, a partir de avaliações nacionais com metas e padrões de aprendizagem alcançáveis que visa fortalecer as reformas educacionais por meio do que chama de eficácia dos sistemas educacionais". (Hypolito, 2019, p. 189)

Nos três eixos apontados pelo autor, em que define as orientações que devem ser assistidas, o currículo surge como um dos ideais que carrega a finalidade de padronizá-lo, tendo em vista a qualidade da aprendizagem e o alcance de metas. Essa temática está associada aos processos avaliativos e aos testes padronizados, indicando políticas direcionadas a umareforma de caráter global. Nessa perspectiva, já percebemos que as práticas curriculares e avaliativas estão intrinsecamente relacionadas, no momento em que formam uma área de afinidade, porém com encaminhamentos e implicações diversas no cotidiano escolar e nas pesquisas científicas. 
O Brasil tem sido um país com grandes influências das políticas inspiradas em critérios mercadológicos e empresariais, sustentando aparelhos de controle na educação. Em contrapartida, o discurso neoliberal, em busca do senso comum, demonstra a necessidade de investir nas escolas, resgatando valores caros às sociedades. Preocupar-se, portanto, com o processo de ensino e aprendizagem seria uma forma de solucionar entraves em nosso país. De acordo com Freitas (2012), as políticas educacionais brasileiras, fincadas no conservadorismo e neoliberalismo, parecem ser adotadas mais por uma imposição política e econômica do que por evidências empíricas de que elas resolveriam os problemas educacionais brasileiros.

Nesse panorama, em que o contexto histórico é crivado por políticas educacionais que apontam uma arena de confrontos, surge o discurso referente ao sistema de avaliação em larga escala e, consequentemente, à padronização de testes, exames e provas. Diante disso, a lógica de uma base nacional orientando a construção e o exercício do currículo torna-se evidente. Essas questões, por sua vez, trouxeram aos grupos neoliberais o apoio a um currículo no país que pressuponha uma homogeneização de cultura, no sentido de contemplar algumas vozes e ignorar outras. Vale esclarecer e destacar o posicionamento de Hypolito sobre o contexto local e global que a reforma curricular da BNCC foi constituída, permeado por grupos de interesses a instituições ligadas a grupos denominados de "Todos pela Educação" e por lobbies de fundações, institutos e entidades, com ou sem fins lucrativos, "com interesses muito definidos em torno de um mercado educacional bilionário que envolve venda de materiais pedagógicos, consultorias privadas e prestação de serviços, a fim de substituir o que hoje é realizado pelas escolas e pelo sistema público de educação". (Hypolito, 2019, p. 194)

Num campo de disputas, então, a BNCC marca a dinâmica educacional com argumentos defensores de alguns, mas também com falas de repúdio de outros. Sendo assim, vale frisar que o currículo não é apenas um emaranhado neutro de conhecimentos, que, de certo modo, aparece em livros didáticos e salas de aula. Sempre é resultado de uma tradição seletiva, da seleção realizada por alguém, da visão que algum grupo carrega a respeito do conhecimento percebido como legítimo. Na verdade, ele é produzido por meio dos conflitos, tensões e compromissos direcionados à cultura, à política e à economia que organizam e desorganizam um povo.

O processo de elaboração e a vivência do currículo, aqui exposto, sinalizam o realce da exclusão, pois o trabalho escolar não é desinteressado, seja em relação aos conteúdos e à avaliação da aprendizagem, seja nas discussões sobre os valores disseminados nesse espaço. É interessante salientar que as diferentes abordagens referentes ao currículo e à avaliação caminham lado a lado não simplesmente em teorias, como também nas práticas presentes nas unidades de ensino e aprendizagem. Nesse ponto, portanto, daremos ênfase a um curto debate acerca da avaliação da aprendizagem, considerando as suas interfaces na história da educação brasileira.

Partindo da premissa que a avaliação da aprendizagem relaciona-se significativamente com o currículo, desde as suas concepções às finalidades, esta parte do trabalho visa traçar uma reflexão acerca do ato de avaliar em seu contexto histórico e as amarras que demarcam um percurso de controle e poder. Essas questões parecem bem oportunas, devido ao instante que vivenciamos na política educacional, no qual a Base Nacional Comum Curricular apresenta-se como um documento de força, de tomada de decisões e contendas.

Retomando a história da educação brasileira, vale destacar o Manifesto dos Pioneiros da Educação Nova (Azevedo et al., 1932), que trouxe posicionamentos e ideias de um contexto escolar de caráter público, laico e obrigatório. Nesse âmbito, o aluno é percebido como centro do processo educativo, em que a escola é um espaço de formação de atitudes e de valorização da autoaprendizagem. Tornou-se, então, uma base política e de modernidade que, de certa maneira, sustentou a educação e a sociedade no país na busca pela organização de um sistema educacional que atendesse às urgências da estrutura moderna construída naquela época no país. 
Precisamos assinalar que esse Manifesto tinha em vista a universalização da escolarização, cujas pessoas com melhores condições financeiras não fossem os únicos beneficiados pelo conhecimento escolar. Para os pioneiros, esse documento renovaria os olhares dos professores e motivaria a evolução fundamental à administração dos serviços educacionais. É dentro dessa perspectiva que a Educação Nova articula-se e concebe a educação como sinônimo de avanço e de desenvolvimento oriundo do movimento político permeado no campo educacional.

Diante das lutas presentes naquele momento histórico, algumas práticas escolares destacavam-se como mecanismos de controle no intuito de propiciar a ordem no cenário escolar e, consequentemente, nas transformações sociais. Com o passar do tempo, o ciclo de reformas educacionais trouxe à tona questões que representavam, e de algum modo ainda representam, um jogo de confrontos e de relações de poder. Nesse ponto, porém, daremos ênfase à avaliação da aprendizagem, visto que é o nosso objeto de estudo.

Após alguns debates acerca do Manifesto dos Pioneiros, Gatti (2014) assegura que, por volta da década de 1960, a preocupação com os processos avaliativos escolares tornou-se mais explícita e com critérios, até certo ponto claros. Entretanto, as discussões a respeito da avaliação da aprendizagem ainda surgiam direcionadas a um público mais restrito e de forma solta e, algumas vezes, embaraçosa. Sobre isso, a autora menciona que "foi nesse movimento que alguns profissionais começaram a receber formação mais aprofundada na área de avaliação de rendimento escolar, vinculada à teoria da medida e aos conhecimentos sobre elaboração de testes objetivos, sua validade e fidedignidade" (Gatti, 2014, p. 11).

Após essas inquietações, no final dos anos oitenta, começou a aparecer, no cenário educativo, o interesse em compreender e melhor desenhar o desempenho escolar dos estudantes dos diversos níveis da educação básica. Com base em prerrogativas direcionadas ao juízo de valor, seriação, classificação, o ato de avaliar despontou em debates com o intuito de se perceber como ferramenta estática centrada apenas na verificação.

Esses parâmetros são acentuados devido aos resquícios deixados pela história, como bem acentuam alguns estudiosos. Conforme Luckesi (1995), a avaliação tem sua origem na escola moderna com a prática de provas e exames que se sistematizou a partir dos séculos XVI e XVII,com a cristalização da sociedade burguesa. Dessa maneira, a pedagogia tradicional emergiu e aperfeiçoou os seus mecanismos de controle, com foco na seletividade escolar.

Dessa forma, a avaliação desempenha uma função disciplinadora, buscando considerar o julgamento de valor quando atribui notas e foca significativamente na quantidade para garantir excelência de aprendizagem. Essa prática, portanto, dá ao professor a autoridade e o controle para avaliar o conhecimento escolar e sustentar um sistema dominador. A ausência de uma atividade diagnóstica que desse suporte a práticas inovadoras torna a avaliação da aprendizagem um castigo escolar que resulta da evidência de muitos erros.

Com o passar dos anos, observamos que o ato de avaliar o conhecimento escolar limitava-se à intenção de verificar e classificar o sujeito. Esse processo de seleção a partir da avaliação perdurou durante anos na educação brasileira e, de certo modo, ainda é visto, muitas vezes, veladamente. Cabe frisar que a avaliação da aprendizagem não aponta um avanço que configura uma correspondência com práticas e políticas direcionadas ao diagnóstico inicial e provocador de um desenvolvimento de ações que valorizem a qualidade do processo de ensino e aprendizagem.

Sob tal perspectiva, Libâneo (2004) acredita que tratar de qualidade na educação é mais do que supervalorizar os resultados advindos das avaliações, ou classificar escolas em virtude desses resultados, ou ainda incentivar a competição entre elas. $\mathrm{Na}$ verdade, torna-se necessário repensar a avaliação enquanto instrumento que viabiliza a melhoria da apropriação da aprendizagem significativa e não difundir o ideal de mecanismo que sustenta o controle e as relações de poder que, decerto, são mantidas através da autoridade de um grupo - seja ele constituído por professores, gestão escolar, secretaria de educação etc. 
Considerando que a avaliação da aprendizagem, muitas vezes, é compreendida como um produto, revelada no final de uma verificação, propomos, neste ponto, uma reflexão acerca da ação de avaliar o conhecimento escolar perpassando as orientações epistemológicas e pedagógicas apresentadas na Base Nacional Comum Curricular. Essa Base, por sua vez, desponta, nos dias atuais, como uma política educacional amparada pelos ideais neoliberalistas emergentes numa arena de disparidades frente à previsão de qualidade única para todo o país.

Sobre as políticas educacionais brasileiras, Arroyo (2011, p. 88) destaca que: "Os documentos de políticas e as justificativas de diretrizes nacionais refletem esse ideal de unicidade como sinônimo de igualdade de direitos. Educação (em abstrato), direito (em abstrato) de todo cidadão (abstrato). Sem rostos. Sem sujeitos históricos, concretos, contextualizados". A BNCC surge como um documento de caráter normativo que atende à fala anterior, poistem, como interesse, uma educação de qualidade a todos os brasileiros, num modelo em que o Estado tem participação mínima e as grandes empresas destacam-se.

Conforme a Base, os alunos precisam alcançar as "competências", isto é, habilidades que nortearão o trabalho nas escolas e dos professores da Educação Básica com os seus respetivos componentes curriculares. Assim, a avaliação da aprendizagem é uma ferramenta no processo educativo que precisa atender às prerrogativas apontadas pela Base, visto que são questões que se relacionam todo o tempo.

Vale destacar que, de acordo com a Constituição da República Federativa do Brasil de 1988 (1988, p. 24), em seu art. 210, "serão fixados conteúdos mínimos para o ensino fundamental, de maneira a assegurar formação básica comum e respeito aos valores culturais e artísticos, nacionais e regionais". Observamos, então, que é de competência da União determinar os objetivos e os conteúdos gerais do currículo que a escola, junto à comunidade, estabelece como os caminhos necessários para atingir as metas descritas na BNCC.

A Lei de Diretrizes e Bases da Educação Nacional (LDBEN) 9394 (1996) reforçou a necessidade da Base apontando no art. 26 que: "Os currículos da educação infantil, do ensino fundamental e do ensino médio devem ter base nacional comum, a ser complementada, em cada sistema de ensino e em cada estabelecimento escolar, por uma parte diversificada, exigida pelas características regionais e locais da sociedade, da cultura, da economia e dos educandos." (LDBEN, 1996, p. 19).

O texto da LDBEN (1996) faz alusão ao alinhamento dos conteúdos que constituem o currículo da Educação Básica e, para isso, precisam seguir as orientações de uma base nacional comum. Assim, é proposta uma equidade através de um conjunto de aprendizagens que assegure o desenvolvimento que, por sua vez, todo sujeito tem direito. Assim sendo, consoante aos marcos legais anteriores, a Lei no 13.005 (2014) promulgou o Plano Nacional de Educação (PNE), reiterando a necessidade de pactuar a União, Estados, Distrito Federal e Municípios, no intento de estabelecer diretrizes pedagógicas para a educação básica e a Base Nacional Comum dos Currículos, respeitando os direitos e os objetivos de aprendizagem e as diversidades regional, estadual e local (Lei 13.005, 2014).

Após a contextualização da BNCC no contexto histórico e de legislação, cabe-nos situar a avaliação da aprendizagem e refletir a sua movimentação, concepção e os seus nortes no interior de uma pauta apoiada pelas políticas neoliberais. Segundo Galvão (1997), o centro de toda prática neoliberal é o mercado e, por conseguinte, o consumo. Diante disso, a educação deixa de ser parte do campo sociopolítico e ingressa num sistema mercadológico.

A avaliação da aprendizagem, considerando a escola como uma empresa, é percebida enquanto estratégia de regulação da educação, manifestada por meio de provas, exames e testes. Nesse ponto, avaliar significa motivar a concorrência entre escolas, quando ocorre a avaliação em larga escala; e entre os alunos, no momento que trata de avaliação da aprendizagem. É muito importante a análise de Freitas (2012, p. 48) ao pontuar que: "As políticas de avaliação centralizadas se esquecem que não basta o dado do desempenho do aluno ou do professor coletado em um teste ou questionário e seus fatores associados. É preciso que o dado seja "reconhecido" como "pertencendo" à escola. Medir 
propicia um dado, mas medir não é avaliar. Avaliar é pensar sobre o dado com vistas ao futuro". Nesse sentido, notamos uma crítica com relação às políticas de avaliação que centralizam no dado com fim, resultado e não com perspectiva de alargar o conhecimento futuro. É preciso rever os olhares fincados à avaliação, percebendo que esta nãopode concentrar-se em simplesmente obter notas, mas, a partir delas, buscar potencializar melhor o aprendizado do aluno.

Considerando o exposto, esta pesquisa tem como objeto de estudo a avaliação da aprendizagem com foco nos dispositivos apresentados na Base Nacional Comum Curricular, documento de caráter normativo aprovado pelo Conselho Nacional de Educação em dezembro do ano de 2017. Avaliar é uma ferramenta pedagógica complexa e ampla que desperta muitas discussões, uma vez que suscita inquietações em seu campo. Villas Boas (2008) chama a atenção para a importância de se avaliar as aprendizagens e não, simplesmente, a aprendizagem, porque o termo tratado no plural assegura, em seu significado, o envolvimento de todos os sujeitos educativos que atuam na escola e que avaliam e são avaliados.

Vale ponderar que a questão que norteou o estudo é a seguinte: Qual a proposta da avaliação da aprendizagem, a partir das políticas neoliberais implementadas pela Base Nacional Comum Curricular? A investigação objetivou-se, portanto, em refletir sobre a proposta da avaliação da aprendizagem, a partir das políticas neoliberais implementadas pela Base Nacional Comum Curricular. Esse objetivo, por sua vez, desdobrou-se em dois objetivos específicos que são: discutir a avaliação da aprendizagem na seara da BNCC e apresentar os enfoques dados à avaliação da aprendizagem sob o olhar da BNCC.

\section{Metodologia}

Partindo do pressuposto de que "a ciência tem como objetivo fundamental chegar à veracidade dos fatos" (Gil, 2017, p. 27), a pesquisa torna-se uma atividade cuidadosa que tem em vista o estudo e a descoberta de novas questões, possibilitando a ampliação e a verificação do conhecimento já existente. Caracteriza-se por um processo sustentado pela seriedade no decorrer das leituras, no qual se preza pelo rigor da construção e reflexão de dados obtidos em campo.

Essa investigação é resultado de um estudo sustentado na abordagem qualitativa, tendo em vista a reflexão da avaliação da aprendizagem sob os olhares da Base Nacional Comum Curricular. De acordo com Creswell e Creswell (2021), a abordagem qualitativa da pesquisa é voltada para o entendimento que os participantes atribuem a um problema social ou humano, a coleta das informações é realizada no ambiente do participante e a análise das informações é feita de forma indutiva.

Diante disso, optamos pela pesquisa de campo, a qual se realizou em três instituições de ensino da rede pública municipal de uma cidade baiana. A pesquisa de campo busca "fatos e fenômenos tal como ocorrem espontaneamente" no ambiente natural. (Lakatos \& Marconi, 2017, p. 186)

Seguindo essa linha, utilizamos alguns recursos que facilitaram a obtenção e a análise de dados fundamentais ao desenrolar da atividade proposta e que apresentamos na sequência. A pesquisa teve como instrumentos a entrevista semiestruturada e a análise documental. A escolha destas deu-se pelo fato de facilitar o acesso às opiniões dos envolvidos e ao conhecimento de informações acerca do objeto de estudo tratado neste trabalho. Em se tratandoda entrevista, Lakatos e Marconi (2017) assinalam que cabe fixar que a sua finalidade é obter informações a respeito de determinado assunto ou problema, além de ser uma importante ferramenta de trabalho nos mais variados campos das ciências sociais.

Para a consecução dessa etapa, a entrevista desenvolveu-se com três coordenadoras pedagógicas que atuam no ensino médio na rede ensino municipal. Todas pertencem a faixa etária de 35 a 45 anos, com atuação na área de coordenação, variando entre dois anos e meio a cinco anos. Duas coordenadoras são graduadas em Pedagogia e a terceira, em Letras. Dentre elas, uma é especialista em Psicopedagogia e outra em Gestão Pública. A atividade realizou-se por meio do aplicativo de mensagens WhatsApp na primeira quinzena do mês de maio do corrente ano, quando as perguntas foram 
encaminhadas e respondidas em seguida. Infelizmente, não foi possível realizar encontros frente a frente em atendimento as recomendações de distanciamento social da Organização Mundial da Saúde para o enfrentamento da Covid-19.

É importante ponderar que as participantes da pesquisa são mencionadas neste trabalho como $\mathrm{C} 1, \mathrm{C} 2$ e C3 com o intuito de preservar a identidade e, assim, garantir o sigilo e anonimato conforme preceitua a resolução do Conselho Nacional da Saúde 510, do Ministério da Saúde (2016), bem como a livre e espontânea participação. Além disso, optamos por resguardar os espaços investigados, ou seja, as instituições escolares que respeitosamente contribuíram com o presente estudo.

Com relação à análise documental, esta permeou o universo da Base Nacional ComumCurricular (BNCC). Partindo da premissa de que o foco, neste trabalho, é a reflexão da avaliação da aprendizagem à luz da Base, não podíamos desconsiderar esse recurso metodológico. Conforme Sá-Silva, Almeida e Guidani (2009), a análise documental refere-se à riqueza de informações que se pode extrair e resgatar dos documentos, justificando o seu uso em diversas áreas das Ciências Humanas e Sociais. Desse modo, ela possibilita a ampliação do entendimento de objetos cuja compreensão necessita de contextualização histórica e sociocultural.

A partir das informações obtidas no decorrer da pesquisa, o procedimento metodológico utilizado para a análise sustentou-se na análise de conteúdo que, segundo Bardin (2011, p. 44), é: "Um conjunto de técnicas de análise das comunicações visando obter, por procedimentos sistemáticos e objetivos de descrição do conteúdo das mensagens [...] que permitam a inferência de conhecimento relativos às condições de produção/recepção (variáveis inferidas) destas mensagens".

Conforme Bardin (2011) a referida análise é dividida em três fases: a) pré-análise, b) exploração do material e c) tratamento dos resultados, inferência e interpretação $\mathrm{Na}$ primeira fase, realizamos a leitura flutuante e a preparação do corpus de análise que, por sua vez, constituiu-se pela Base Nacional Comum Curricular e todas as respostas obtidas nas entrevistas. Na fase de exploração do material, procedemos, então, à codificação obedecendo a regra de recorte do texto, em unidades de registro pelo tema, e em unidades de contexto, pela frase. Em seguida, procedemos à categorização das informações pelo processo semântico. A categorização foi pelo método indutivo agrupada à posteriori. Por fim, na terceira fase, foi realizado o tratamento dos resultados e, por conseguinte, a inferência e a discussão dos dados.

Após essas etapas, a análise de conteúdo resultou em duas categorias finais, que são apresentadas a seguir: Categoria 1: Avaliação daaprendizagem na seara da BNCC e Categoria 2: Avaliação da aprendizagem no universo da pesquisa. Discutiremos tais categorias na próxima seção.

\section{Resultados e Discussão}

Neste trecho, pontuamos com mais atenção algumas questões que são imprescindíveis à reflexão dos resultados obtidos no decorrer da pesquisa realizada em campo. Vale destacar que o intento do estudo concentra-se em refletir sobre a proposta da avaliação daaprendizagem, a partir das orientações apresentadas na Base Nacional Comum Curricular. Nesta seção, discutiremos as categorias em que as informações foram organizadas durante o processo de análise de conteúdo:

\section{Categoria 1: Avaliação da aprendizagem na seara da BNCC}

Esta categoria revela a avaliação da aprendizagem na seara da Base Nacional Comum Curricular, com base na análise de conteúdo que foi realizada no texto da BNCC. Considerando que a BNCC despontou em um cenário de disputas frente às políticas neoliberais, como já foi visto aqui, não há como discutir a Base fora de seu arrolamento com a proposta das avaliações externas e, consequentemente, internas. A busca, neste sentido, dá-se pela padronização de conteúdos e, consequentemente, do ato de avaliar junto à utilização de ferramentas mais eficientes para apresentar os resultados. Todavia, 
uma indagação aparece: Padronizar conteúdose sistema avaliativo externo e interno da escola favorece as ações democráticas defendidas pelas legislações brasileiras?

A elaboração da BNCC acontece em meio à necessidade de alinhar ainda mais o currículo escolar aos indicadores exigidos nas avaliações em larga escala, como, por exemplo, a Prova Brasil e o Programa Internacional de Avaliação de Alunos (PISA). Nessa direção, a Base explicita a importância da organização curricular por competências, uma vez que são referências adotadas:

[...] nas avaliações internacionais da Organização para a Cooperação e Desenvolvimento Econômico (OCDE), que coordena o Programa Internacional de Avaliação de Alunos (Pisa, na sigla em inglês), e da Organização das Nações Unidas para a Educação, a Ciência e a Cultura (Unesco, na sigla em inglês), que instituiu o Laboratório Latinoamericano de Avaliação da Qualidade da Educação para a América Latina (LLECE, na sigla em espanhol). (BNCC, 2017, p. 13)

Nesse recorte, notamos a relação evidente entre a BNCC e as avaliações em larga escala que, consequentemente, reflete no direcionamento e articulação das práticas que constituem a avaliação da aprendizagem. Isso significa, portanto, que o ato de avaliar o conhecimento fica, de certo modo, condicionado ao interesse de atender às prerrogativas de competências focadas em indicadores cobrados em avaliações de maior escala e amplitude nacional e até mundial.

Na verdade, essa padronização de currículo e avaliação lembra-nos um sistema de gerencialismo, que é pretendido pela política neoliberal, que explicita a preocupação com o atendimento de indicadores cobrados pelas organizações de caráter internacional e nacional. Nessa linha de pensamento, Barreto (2016, p. 778) esclarece que “[...] não há como discutir as questões relativas à BNCC fora da sua relação com a proposta de avaliação externa: quanto mais específicas forem as descrições, maior será a padronização e mais eficientes os instrumentos para aferir resultados”. As atividades e os exames, conforme a BNCC, devem ser sustentados no viés da avaliação formativa, a qual defende o processo de aprendizagem tentando evitar a manifestação da seleção e classificação. Porém, além desse ponto, há as cobranças advindas dasavaliações externas sobre as internas o que, decerto, interfere na prática docente e na aprendizagem dos alunos. É interessante expor alguns pontos a respeito das orientações da Base para que o ato de avaliar aconteça de forma que preconize o desenvolvimento global do estudante.

Na perspectiva de que o currículo escolar é um dos elementos delimitadores que compõem a prática pedagógica, notamos as relações que mantêm com a avaliação da aprendizagem. Nesse contexto atual, a BNCC indica que as decisões pedagógicas devem estar orientadas para o desenvolvimento de competências outrora apontadas a cada ano escolar. Em se tratando de disposições que circundam o processo de ensino e aprendizagem, atentamos o nosso olhar à prática da avaliação que, por sua vez, precisa fortalecer ações que assegurem os conhecimentos essenciais definidos na Base. Sobre isso, o documento assinala que "a sociedade contemporânea impõe, portanto, um olhar inovador e inclusivo a questões centrais do processo educativo: o que aprender, para que aprender, como ensinar, como promover redes de aprendizagem colaborativa e como avaliar o aprendizado". (BNCC, 2017, p. 14)

A partir desse recorte, percebemos a necessidade de uma visão diferenciada e mais abrangente no que tange aos quesitos fundamentais do processo educativo, dentre eles, a avaliação do aprendizado. Sendo assim, contrapondo a ideia de que a BNCC é um documento marcado pelo gerencialismo, o qual visa ao controle dos resultados educacionais, trazendo o discurso que reforça a definição das aprendizagens essenciais a serem trabalhadas nas redes pública e privada, tendo como norte todas as dimensões formativas do sujeito.

$\mathrm{Na}$ BNCC, as práticas avaliativas são vistas com uma atuação de maneira mais ampliada, rompendo a ideia reducionista que valoriza apenas o campo cognitivo e intelectual. Assim sendo, a partir da regulamentação de um referencial curricular comum, a avaliação é notada como parte de um conjunto de decisões que se articulam às ações do currículo. Esse 
cenário exige, pois, um processo de envolvimento e participação das famílias e da comunidade, sustentado em "construir e aplicar procedimentos de avaliação formativa de processo ou de resultadoque levem em conta os contextos e as condições de aprendizagem, tomando tais registros como referência para melhorar o desempenho da escola, dos professores e dos alunos". (BNCC, 2017, p. 17)

Sustentada no caráter formativo, os alunos assumem uma postura de maior protagonismo no sistema de avaliação apresentado pela BNCC, sem perder de vista as aprendizagens essenciais outrora estabelecidas e a dinâmica do currículo. Cabe frisar que, em cada modalidade que compreende a Educação Básica (Educação Infantil, Ensino Fundamental I e II e Ensino Médio), podemos notar direções diferenciadas a respeito das práticas avaliativas. Porém, algumas questões são direcionadas a qualquer etapa escolar, nas quais estãoorganizadas em competências gerais. Nelas, observamos a importância de valorizar e utilizar osconhecimentos historicamente construídos, exercitar a curiosidade intelectual, considerar as diversas manifestações artísticas e culturais (sejam locais ou mundiais), utilizar e criar tecnologias digitais de informação e comunicação etc.

É importante destacar que é preciso dar ênfase a uma análise global e integral do estudante, o que dá abertura a novos formatos de avaliação contínua e sistemática. Mediante isso, a BNCC apresenta os objetos de conhecimento, as habilidades pretendidas em cada campo,entretanto, não especifica os estilos das práticas avaliativas. Podemos dizer que as provas escritas continuam sendo significativas, mas outros instrumentos devem ser inseridos na rotina escolar para atender às recomendações da Base e, sobretudo, potencializar a formação de sujeitos autônomos e críticos. Produções ou trabalhos individuais e coletivos, seminários, autoavaliações, dramatizações, portfólios, construção e exposição de painéis, dentre outras, sãoferramentas que vêm somar e fortalecer a avaliação formativa.

Outro ponto que merece ser apreciado na escolha do aparato avaliativo, na tentativa de garantir as orientações da Base, é a valorização da tecnologia no momento de avaliar. Sobre isso, o documento, em sua quinta competência geral da Educação Básica, afirma que é preciso: “Compreender, utilizar e criar tecnologias digitais de informação e comunicação de forma crítica, significativa, reflexiva e ética nas diversas práticas sociais (incluindo asescolares) para se comunicar, acessar e disseminar informações, produzir conhecimentos, resolver problemas e exercer protagonismo e autoria na vida pessoal e coletiva". (BNCC, 2017, p. 9)

Sendo assim, o universo tecnológico aumenta ainda mais os horizontes no instante de avaliar os estudantes em sua vida escolar. Atividades como enquetes, fóruns de discussão, produção oral em plataformas digitais, dentre outras alternativas, são artifícios que somam na avaliação formativa. Na atualidade, diante da pandemia da Covid-19, essas opções podem ser muito relevantes na configuração de um ensino híbrido ou educação remota. Enfim, de acordo com as ideias apresentadas no presente estudo, a partir desse ponto, propusemos-nos a discutir a avaliação da aprendizagem desenvolvida no espaço investigado.

A partir dessa discussão, percebemos que a avaliação da aprendizagem na conjuntura da Base Nacional Comum Curricular pode ser observada em dois vieses: primeiro, como um instrumento gerencialista e de controle, atendendo às preocupações com as avaliações externase, segundo, enquanto recurso pedagógico e formativo com vistas ao protagonismo do aluno e a sua análise global e integral.

\section{Categoria 2: Avaliação da aprendizagem no universo da pesquisa}

Esta categoria apresenta o conteúdo sobre a avaliação da aprendizagem com foco na BNCC sob a perspectiva das entrevistadas. A avaliação da aprendizagem é uma temática que ainda provoca muitas inquietações e polêmicas, vale considerar que é uma ferramenta fundamental ao processo educativo e, por isso, precisa ser repensada constantemente. Entendemos, pois, que avaliar os saberes na instituição de ensino é um modo de acompanhar a vida escolar do indivíduo, 
buscando os melhores meios para promover o rompimento das ideias do senso comum e a apropriação do conhecimento científico.

Conforme excerto de uma entrevista "avaliar é observar se o alunoestá desenvolvendo ou já desenvolveu a capacidade de utilizar o conceito como instrumento do pensamento e, deve ser objeto da atenção dos professores no momento da elaboração e acompanhamento da avaliação" (C1). Podemos depreender desse discurso que a entrevistada percebe a avaliação como uma ferramenta capaz de atentar ao que o aluno está aprendendo ou já aprendeu e, assim, ser vista com cautela pelos professores. Notamos que ela não se sente peça importante nesse processo, uma vez que direciona atenção apenas ao corpo docente. Em contraposição, outra entrevistada mostra-se envolvida no momento fixando que: "A avaliação é uma forma da gente acompanhar o que o aluno está aprendendo e buscar, através dela, os melhores meios para isso. Sei que não é fácil avaliar o aprendizado dos alunos, mas vejo como uma forma importante de, realmente, poder fazer um acompanhamento da vida escolar do aluno junto com os professores" (C2).

Nessa linha, a participante C3 menciona a necessidade de um trabalho conjunto entre docência e coordenação no processo avaliativo que circunda o espaço educativo. Além dessa questão, foi questionado sobre o conceito atribuído à Base, na tentativa decompreender a visão dos espaços investigados. Sendo assim, foi-nos afirmado que "a BNCC ainda não é algo claro para mim, então penso que deveria discutir mais sobre isso nas escolas. Por essa razão e também devido à pandemia, muita coisa na escola ainda não tem reflexos da Base" (C3). Notamos, desse modo, que a referida entrevistada não sente segurança ao tratar da BNCC, uma vez que salienta a falta de clareza no tema. Sobre isso, vale acrescentar o registro de que "a Base Nacional Comum Curricular define os direitos de aprendizagens de todos os alunos, independente de região, raça ou classe socioeconômica, todos os estudantes do Brasil devem aprender as mesmas habilidades e competências ao longo da sua vidaescolar" (C1).

Com base nesses recortes, surgem-nos algumas indagações, tais como: Quais relações permeiam os campos da avaliação no cenário da BNCC? O movimento mais restrito entre as diretrizes curriculares e o ato de avaliar o conhecimento escolar apareceu com o despontar da Base? Neste sentido, vale pontuar que a avaliação da aprendizagem, no novo paradigma, é um processo mediador na construção do currículo e encontra-se intimamente relacionada à gestão da aprendizagem dos alunos (Perrenoud, 2004). Mediante o exposto, percebemos que, antes da aprovação da Base, já se falava na necessidade de dialogar com a avaliação junto aocurrículo, uma vez que a primeira medeia a elaboração do segundo.

Neste aspecto, o município precisa considerar as orientações feitas pela Base, buscando perceber os recursos de avaliação como práticas pedagógicas que ultrapassem os limites de notas e conceitos. Em contrapartida, a BNCC aponta grande valorização às avaliações externas, em que enaltece os aspectos quantitativos, fato que emerge na construção, aplicação e acompanhamento das atividades avaliativas da aprendizagem. Acerca desse quesito, uma de nossas entrevistadas registrou que o Projeto Político Pedagógico não está adaptado à Base: "O PPP da Escola é bem antigo e com poucas informações da Escola, a última atualização do PPP foi no ano de 2016. Tentei atualizar o PPP em 2019, mas por contada construção do Novo Currículo [da cidade x] , foi solicitado pela Secretaria Municipal de Educação a não atualização do PPP, neste ano, até que fosse elaborado onovo Currículo adequado à BNCC que só foi finalizado no final de 2020 em meio a Pandemia da Covid19" (C1).

A Base apresenta as competências gerais e determina as aprendizagens essenciais a cada ano. Neste sentido, o PPP precisa corresponder a essas orientações, repensando osinstrumentos avaliativos e demais práticas educativas. De acordo com Diniz (2019), o Projeto Político Pedagógico é um documento que define a identidade e as diretrizes que serão implementadas na escola para a aprendizagem e formação integral dos alunos. Ele serve, portanto, como guia que considera todas as atividades da instituição, conforme a realidade da própria escola e os objetivos dispostos pela BNCC. 
A entrevistada C3 salientou que gostaria de adequar o PPP às exigências daBase, mas devido à falta de segurança no assunto e ao momento de pandemia, esse feito tem setornado mais difícil e desafiador. Ainda sob essa perspectiva, cabe frisar que "não é fácil refazer o PPP, sem os encontros presenciais com a comunidade interna e externa da escola e, além disso, preciso conhecer com mais propriedade a respeito da Base" (C2). Diante desse extrato, notamos a dificuldade de reconstruir a avaliação da aprendizagem, segundo os olhares da BNCC e as urgências da situação atual, em que ainda assistimos ao isolamento social.

Em contrapartida aos entraves oriundos da pandemia, uma das entrevistadas comentou a respeito da forma como a avaliação da aprendizagem vem se adequando aos apontamentos da BNCC, como mostra $\mathrm{C} 1 \mathrm{em}$ seu depoimento, "Fica mais fácil entender o que é esperado que o aluno aprenda e acompanhar os passosdesse aprendizado, ajuda no planejamento e em maior clareza das potências e desafios de cada um na turma". Além disso, a informante destaca que: "Utilizamos rotinas semanais para verificar a aprendizagem do aluno, assim é possível saber se a turma assimilou os conhecimentos necessários, o objetivo é identificar dificuldades de aprendizagem para a correção na semana seguinte sem adentrar em conteúdos novos", (C1). A entrevistada deixa claro o ato de avaliar o conhecimento à luz da BNCC, mesmo sem as adaptações feitas no PPP, facilitando o processo de planejamento e acompanhamento do aprendizado. Para tanto, é utilizada a rotina semanal com o intuito de verificar os saberes compreendidos, romper as dificuldades de aprendizagem para os próximos dias, antes de submergir em assuntos novos.

Prosseguindo em nossa análise, destacamos a opinião de outras investigadas que a avaliação da aprendizagem não passou a acontecer com um formato diferenciado, isto é, partindo das perspectivas da Base Nacional Comum Curricular, acentuando ainda um certo desconhecimento a respeito do assunto. Na ocasião, reforçaram a importância de a Secretaria Municipal de Educação abrir espaço para o debate referente à Base, quando afirmaram: "Nem sempre a gente tem tempo ou oportunidade para conhecer e discutir sobre a BNCC. Penso que a Secretaria de Educação (referindo-se a nível municipal) deveria oferecer cursos para nós. Precisamos conhecer esse documento para rever nossa prática na escola, né?” (C2). Do mesmo modo, outra participante acrescenta que: "Às vezes, vejo alguns textos relacionados à BNCC na internet, em artigos etc. Mas, o trabalho é bem corrido, então é difícil apropriar do tema. Creio que a SEMED, depois da pandemia, poderia facilitar nesse sentido e promover espaços para que as discussões sobre isso acontecessem. Isso ajudaria muito a gente" (C3).

Após analisarmos os excertos das entrevistas, tornou-se evidente que o universo pesquisado percebe a avaliação da aprendizagem como uma ferramenta necessária ao acompanhamento da vida escolar do aluno. A entrevistada $\mathrm{C} 1$ salientou que a avaliação deve ser foco do trabalho do professor, contudo, as demais participantes entendem que a avaliação é um recurso que precisa ser desenvolvido de modo coletivo, ou seja, respeitando a parceria entre docentes e coordenação pedagógica.

Partindo do princípio que o "Projeto Político Pedagógico, ao se constituir em processo democrático de decisões, preocupa-se em instaurar uma forma de organização do trabalho pedagógico" (Veiga, 2007, p. 13), entendemos que esse documento precisa trazer a avaliação da aprendizagem sob a perspectiva da Base Nacional Comum Curricular. Nesse contexto, as coordenadoras pedagógicas apontaram a necessidade de rever o PPP, adaptando-o à Base, contudo, visualizam alguns entraves. Foram citadas pelas colaboradoras da pesquisa, portanto, questões como o pouco conhecimento acerca da Base e ainda o momento de pandemia que dificulta os encontros presenciais. As informantes $\mathrm{C} 2$ e C3 enfatizaram que a Secretaria Municipal de Educação (SEMED) poderia oportunizar momentos de discussão referentes à Base, uma vez que elas não sentem segurança para tratar da temática.

Ainda nesse embate, no qual vemos duas entrevistadas apontando a necessidade da SEMED pensar e agir em prol de oportunizar o diálogo acerca da BNCC, vale o respaldo de que o próprio documento afirma a importância de "criar e 
disponibilizar materiais de orientação para os professores, bem como manter processos permanentes de formação docente que possibilitem contínuo aperfeiçoamento dos processos de ensino e aprendizagem”. (BNCC, 2017, p. 19)

\section{Conclusão}

Com base na questão que norteou este estudo e atendendo ao objetivo de refletir sobre a proposta da avaliação da aprendizagem, a partir das políticas neoliberais implementadas pelaBase Nacional Comum Curricular, o estudo conclui que a proposta de avaliação configura-se sob duas perspectivas.

A primeira reflete a avaliação enquanto instrumento gerencialista e de controle e a seguinte o faz num olhar pedagógico e formativo, tendo em vista a análise global e integral do aluno e o seu papel como protagonista no processo educativo.

Sobre essa situação, percebemos que a BNCC defende a avaliação formativa e, com isso, algumas particularidades, tais como: o protagonismo do aluno, a análise global e integral e o respeito aos contextos e às condições de aprendizagem. Esses ideais dão abertura para que haja diferentes métodos avaliativos e, assim, as competências específicas para cada área do conhecimento da educação básica sejam atendidas. No decorrer da pesquisa, ponderações foram feitas com o intento de tornar mais clara a perspectiva da avaliação no cenário da Base, uma vez que a implementação desse documento de caráter normativo permeia a educação brasileira.

É importante salientar que, segundo as participantes da pesquisa, o Projeto Político Pedagógico (PPP) dos espaços investigados não reflete as orientações da Base Nacional Comum Curricular. O PPP é um norteador das práticas e metodologias escolares, o qual apresenta aspirações, metas, bem como os meios para torná-las concretas. Neste sentido, observamos que a avaliação da aprendizagem até o momento não é concebida no universo estudado à luz da Base. Vale salientar, portanto, que esse documento não delimita os instrumentos do processo avaliativo, na verdade, orienta a elaboração das matrizes curriculares quando estabelece as competências e os conteúdos essenciais a cada ano escolar. Sendo assim, apresenta a necessidade de utilizar diferentes métodos avaliativos e buscar o protagonismo dos alunos.

Outro ponto visto no decorrer da investigação é o fato da BNCC valorizar as avaliações externas, no instante em que se preocupa com os resultados em larga escala. Dessa forma, visualizamos uma padronização de conteúdos no processo de ensino e aprendizagem que, por sua vez, precisa ser avaliado no estabelecimento escolar seguindo o viés formativo. Essa padronização corrobora com as prerrogativas de escola democrática garantida pelas leis do nosso país? Em suma, algumas reflexões são feitas durante este trabalho, mas sem perder o atento à problemática que o sustentou.

Nesse afã, notamos que duas coordenadoras sentem a necessidade de a Secretaria Municipal de Educação possibilitar espaços para discussão acerca da Base Nacional Comum Curricular e, assim, facilitar a prática desta no desenrolar do processo educativo. Junto a isso, reforçaram algumas situações que, decerto, dificultam o desenvolvimento da prática avaliativa conforme as recomendações da Base, devido à situação atual de pandemia. Esse contexto não favorece os encontros presenciais entre a comunidade interna e externa da escola, para que o PPP seja revisto e tão logo contemple olhares diferenciados à avaliação.

Observamos, pois, que as coordenadoras pedagógicas compreendem o processo avaliativo do conhecimento como um instrumento fundamental ao acompanhamento da vida escolar do estudante. Todavia, evidenciaram pouca compreensão acerca dos olhares da Base direcionados a essa prática pedagógica.

Em suma, a proposta da avaliação da aprendizagem no universo investigado até o momento não contempla as orientações advindas da Base Nacional Comum Curricular. O fato é decorrente de alguns agravantes, tais como: o entendimento insuficiente de algumas coordenadoras pedagógicas frente ao debate da Base e as dificuldades no tocante à importância dos encontros presenciais entre os membros da comunidade escolar nesse processo, devido à atualidade que abarca a disseminação do coronavírus em nosso país. 


\section{Referências}

Arroyo, M. (2011). Políticas educacionais, igualdade e diferenças. Revista Brasileira de Política e Administração da Educação. RBPAE, 27 (1). https://www.scielo.br/j/es/a/WGyPfcRb7yFJPmFsj5pSxPx/?lang=pt\&format=pdf

Azevedo, F. et al. (1932). A reconstrução educacional no Brasil ao povo e ao governo: Manifesto dos Pioneiros da Educação Nova. Cia. Editora Nacional. https://www.histedbr.fe.unicamp.br/pf-histedbr/manifesto_1932.pdf

Bardin, L. (2011). Análise de conteúdo. Edições 70.

Barreto, R. G. (2016). Entre a Base Nacional Comum Curricular e a avaliação: a substituição tecnológica no ensino fundamental. Educação Social, 37 (136). https://doi.org/10.1590/ES0101-73302016159933

Constituição da República Federativa do Brasil de 1988. (1998). http://www.planalto.gov.br/ccivil_03/constituicao/constituicao.htm

Creswell, J. W., \& Creswell, J. D. (2021). Projeto de Pesquisa: Métodos Qualitativo, Quantitativo e Misto. (5a ed.), Penso

Diniz, G. (2019). Como alinhar o PPP da escola à Base Nacional Comum Curricular? NovaEscola. https://gestaoescolar.org.br/conteudo/2183/como-alinharo-ppp-da-escola-a-base-nacional-comum-curricular

Freitas, L. C. et al. (2012). Avaliação Educacional: Caminhando pela contramão. (4a ed.), Vozes.

Fonseca, M. (1998). O Banco Mundial e a educação brasileira: uma experiência de cooperaçãointernacional. In R. P. Oliveira. (org.), Política educacional: impasses e alternativas. (2a ed.), (pp. 85-122). Cortez.

Galvão, A. M. (1997). A crise da ética: o neoliberalismo como causa da exclusão social. (4a ed.), Vozes.

Gatti, B. A. (2014). Formação inicial de professores para a educação básica: pesquisas e políticaseducacionais. Estudos em Avaliação Educacional, 25 (57) 24-54. https://doi.org/10.11606/issn.2316-9036.v0i100p33-46

Gil, A. C. (2017). Como elaborar projetos de pesquisa. (4a ed.), Atlas,.

Hypolito, A. M. (2019). BNCC, agenda global e formação docente. Revista Retratos da Escola, 13 (25). https://doi.org/10.22420/rde.v13i25.995

Lei $n^{\circ}$ 9.394, de 20 de dezembro de 1996. (1996, 23 de dezembro). Estabelece as diretrizes e bases da educação nacional. http://www.planalto.gov.b r/ccivil_03/LEIS/L9394.htm

Lei $n^{\circ} 13.005$ (2014, 26 de junho). Aprova o Plano Nacional de Educação - PNE e dá outras providências. http://pne.mec.gov.br/18-planos-subnacionais-deeducacao/543-plano-nacional-de-educacao-lei-n-13-005-2014

Libâneo, J. C. Organização e Gestão da Escola: Teoria e Prática. EditoraAlternativa,

Luckesi, C. C. Avaliação da aprendizagem escolar. Cortez.

Lakatos, E. M., \& Marconi, M. de A. Metodologia Científica. (3a ed.), Atlas.

Ministério da Educação. (2017). Base Nacional Comum Curricular. http://basenacionalcomum.mec.gov.br

Ministério da Saúde. (2016). Resolução $n^{o}$ 510/2016. Conselho Nacional de Saúde. http://conselho.saude.gov.br/resolucoes/2016/Reso510.pdf

Perrenoud, P. Os ciclos de aprendizagem: um caminho para combater o fracassoescolar. Artmed.

Sá-Silva, J. R. , Almeida, C. D. , Guindani, J. F. Pesquisa documental: pistas teóricas e metodológicas. Revista Brasileira de História e Ciências Sociais, 1,(1).

Triviños, A. N. da S. Introdução à pesquisa em ciências sociais: a pesquisa qualitativaem educação. Atlas, 2008.

Veiga, I. P. (org.) Projeto Político-Pedagógico: uma construção possível. (23a ed.), Papirus.

Villas Boas, B. M. de F. Virando a escola do avesso por meio da avaliação. Papirus. 